\title{
On-road Air Pollution Exposure to Cyclists in an Agent-Based Simulation Framework
}

\author{
Amit Agarwal ${ }^{1,2 *}$, Ihab Kaddoura ${ }^{1}$ \\ ${ }^{1}$ Transport Systems Planning and Transport Telematics, Technische Universität Berlin, Salzufer 17-19, D-10587 Berlin, Germany \\ 2 Transportation Engineering Group, Department of Civil Engineering, Indian Institute of Technology Roorkee, Roorkee, \\ 247667, India \\ * Corresponding author, e-mail: amitfce@iitr.ac.in
}

Received: 09 June 2018, Accepted: 16 July 2018, Published online: 17 January 2019

\begin{abstract}
Bicycle is not only a sustainable mode of transport but also health benefits of bicycling due to increased physical activities are well cited. However, in urban agglomerations, on-road air pollution exposure to cyclists/pedestrians is a matter of concern which is understudied. This study proposes an approach to calculate the on-road air pollution exposure for drivers of different vehicles in an agent-based simulation framework. In the proposed approach, the breathing rate of different drivers, penetration rate, vehicleoccupancy and background concentration are taken into consideration. The approach is applied to a real-world scenario of Patna, India where non-motorized modes are in abundance. A comparison of total inhaled mass per trip for drivers of different vehicles is made and it is found that cyclists are most exposed user group. An analysis for various background concentrations for different days of the year shows that the contribution of the background concentration has a major effect on the air pollution exposure level. The outcome is spatially analyzed to identify the locations of most affected user groups mapped to their home locations. Further, the on-road air pollution exposure of business-as-usual scenario is compared with a policy case and it is found that a dedicated bicycle track can increase the exposure per trip to cyclists by $40 \%$.
\end{abstract}

Keywords

on-road exposure, emission exposure, background concentration, MATSim

\section{Introduction}

Air pollution in urban areas is caused by a variety of sources, e.g. industry, transport, residential, open-burning etc. Several primary and secondary pollutants in the air are harmful to wildlife, vegetation and human health. People living in dense areas are most exposed to the bad air quality. Some of the negative effects of air pollution on human health are exacerbation of Asthma, impaired lung function, cardiovascular diseases etc. The economic losses due to such negative effects can sum up to significant share of country's gross domestic product (GDP) (Creutzig and He, 2009; van Essen et al., 2011). In urban agglomerations, travelers as well as people doing activities indoor are also exposed to bad air quality. In a transport environment, the modeling of air pollution exposure would require integration of transport models, emission models as well as activity-based models.

In this direction, Gulliver and Briggs (2005) integrate a traffic model, an air pollution dispersion model, a background pollution model and an activity-based model to identify the air pollution exposure. Similarly, de Nazelle et al. (2009) also propose a simulation model to estimate the air-pollution exposure to pedestrian friendly designs. Zhang and Batterman (2013) assess health risks of traffic for on- and near-road persons using an empirical traffic speed-volume relationship. For an arterial, the authors find that on-road and near-road persons' health risk increase sharply with an increase in traffic. These studies mainly focus on showing the importance of the air pollution exposure and then emphasizing on the need to integrate an air pollution exposure model with a transport model for real-world policies. These studies lack in a detailed traffic modeling with dynamic traffic characteristics, emissions from congested traffic, impact on behavioral aspects of the travelers etc.

In the direction of integrating emissions with a transport model, an emission modeling tool (EMT) is proposed 
by Hülsmann et al. (2011) and further improved by Kickhöfer et al. (2013). The objective of the tool is to calculate time-dependent, link and vehicle-specific exhaust emissions based on the static and dynamic vehicle characteristics. In order to evaluate the latter, EMT is integrated with an activity-based transport simulation framework. In order to observe the reaction of travelers on inclusion of emissions costs in the choice model, an internalization approach is proposed by Kickhöfer and Nagel (2016). As expected, the choices made by the travelers are heavily influenced by the emission costs ${ }^{1}$. However, the exposure to exhaust emissions as well as the effect of background air pollution are not included. To overcome the former limitation, Kickhöfer and Kern (2015) propose an approach to calculate air pollution exposure only to people doing activities in the near vicinity. Background air pollution concentrations as well as on-road air pollution exposure is completely ignored. These limitations are addressed in the present study. Adverse effects of the exposure to traffic-related exhaust emissions depend on several factors such as receptor-source distance, source height, vehicle-penetration rate, exposed duration, breathing rate of the driver etc. The impact of negative effects of air pollution exposure is unevenly distributed among drivers; e.g. air pollution exposure is more important for pedestrians and cyclists than car drivers/passengers (Int Panis et al., 2010). Bigazzi and Figliozzi (2014) provide a detailed review of previous studies related to exposure of bicyclists to traffic-related air pollution. Under high traffic conditions, pollutants like hydrocarbon, volatile organic compounds (VOCs) increases significantly near the road because these pollutants are dominated by motorized vehicles. ${ }^{2}$ Bigazzi and Figliozzi (2013) consider on-road exposures in the marginal private and external costs. The authors show that depending on different exposure parameters, the cost of on-road exposure varies between $4 \%$ to $38 \%$. In the similar direction, Bigazzi et al. (2015) investigate the effect of congestion on exposure intensity and exposure duration of motorcyclists.

1 These decisions also depend on the cost component of different negative externalities (e.g. emissions, congestion, noise etc.) and their correlation. Agarwal and Kickhöfer (2018); Kaddoura et al. (2017) propose combined internalization approaches for these externalities and evaluate the driving forces behind the choices made by the travelers under isolated and combined internalization.

2 In presence of sunlight, oxides of nitrogen (NOx) and VOCs undergo complex reactions and produce ozone. High amount of ground-level Ozone is harmful to respiratory systems of people/animals and to crops.
This study proposes an approach to estimate time-dependent, mode- and person specific on-road air pollution exposure for drivers and passengers in an agent-based simulation framework. Though, the approach includes the drivers of car, motorbike as well as bicycle riders, the main focus of the study is to highlight the user group which is at most risk in terms of air pollution exposure. From the authors best knowledge, this approach is not proposed before. The focus of the present study is limited to on-road air pollution exposure, therefore, nearroad air pollution exposure (Kickhöfer and Kern, 2015) is excluded from this study.

\section{Methodology}

\subsection{Travel Simulator}

For all simulation experiments, an agent-based transport simulation framework, MATSim (Horni et al., 2016) is used. In general, an agent represents an individual traveler or group of individual travelers. Minimally, a digital network to represent the physical reality of the roads, travel demand in terms of the daily plans of individual travelers and configuration parameters are required for the simulation. Daily plan of an agent encodes information about the activities, legs between pairs of activities, departure time etc. At least one plan is assigned to each agent.

MATSim controller is embedded into an iterative co-evolutionary algorithm (Balmer et al., 2009). As shown in Fig. 1, the iterative cycle of MATSim simulation framework consists of three parts: mobility simulation (mobsim), scoring and re-planning. In the first step, daily plans of all agents are simultaneously executed on the network using a pre-defined mobility simulation. The default mobility simulation is a queue model (Gawron, 1998; Cetin, 2005) which is suitable for mixed traffic conditions (Agarwal et al., 2015; 2018; Agarwal and Lämmel, 2016) and to simulate the largescale urban agglomerations in reasonable computation time (Balmer et al., 2009). In the next step, all executed plans are evaluated using a configurable utility (or scoring) function (see Nagel et al., 2016, for details). The score of a plan is algebraic sum of utilities gained for performing activities and dis-utilities for traveling to the activity locations. The last step -re-planning- consists of plans' innovation and plans' selection. In the former, an agent gets a new plan by modifying an existing plan according to predefined innovative strategies (e.g. mode choice, route choice, time choices etc.). Usually, a combination of the strategies is used. Only a share of agents is allowed to react under plans' innovation. The rest of the agents select a plan from their choice 


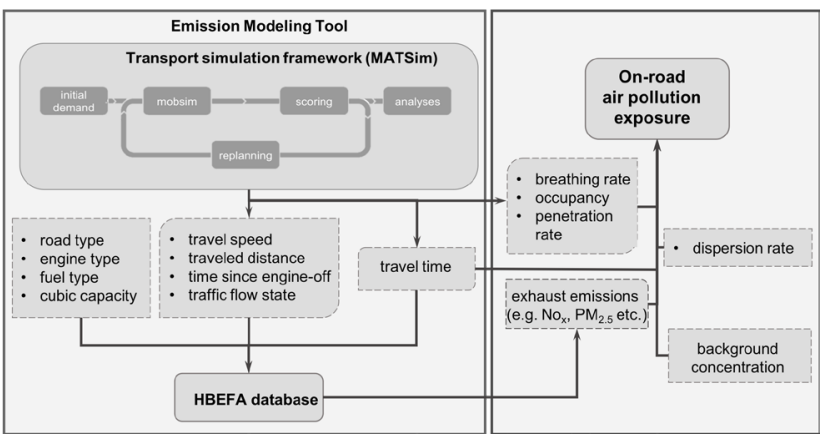

Fig. 1 Integration of on-road air pollution exposure with MATSim controller and emission modeling tool.

set according to a probability distribution which converges approximately to a multinomial logit (MNL) model (Nagel and Flötteröd, 2012). These steps are repeated for a fixed number of iterations i.e. over the iterations, agents learn, react and adapt to the system.

\subsection{Emission Modeling Tool}

The time-dependent, vehicle and link-specific emissions are calculated using an Emission Modeling Tool (EMT). The EMT is proposed by Hülsmann et al. (2011) and further improved by Kickhöfer et al. (2013). To calculate the emissions for variety of vehicles, the EMT is further extended by Agarwal et al. (2017a). The schematic of the emission modeling tool is shown in Fig. 1 and the approach is briefly explained next.

A vehicle type is assigned to every vehicle which encodes static vehicular characteristics (e.g. engine type, cubic capacity, fuel type, age etc.). The dynamic vehicular attributes (e.g. vehicle speed, distance traveled, time since last engine off, etc.), traffic state (free flow, stop-\&-go) are determined by the transport simulation framework (MATSim). The static and dynamic vehicular characteristics, and road type are fed into $\mathrm{HBEFA}^{3}$ database which provides the cold and warm emissions (in [g]). The former is emitted during warm-up phase of the vehicle and therefore also known as cold-start emissions. The latter is emitted during driving of the vehicle and therefore also called as warm-start emissions. Cold and warm emissions are summed up to obtain the total emissions.

\subsection{On-road air pollution exposure}

On-road air pollution exposure due to the emissions (e, in $\mathrm{g} / \mathrm{m}$ ) is estimated using Eqs. (1) to (3). where e is

3 In this study, HBEFA (Handbook Emission Factors for Road Transport) version 3.2 is used. See www.hbefa.net. emissions in $\mathrm{g} / \mathrm{m}$ on each a link emitted by a vehicle, $\Sigma e$ is the total emissions by all vehicles during the travel time $\mathrm{t}$ of an agent. Dispersion of pollution perpendicular to the roadway as area per unit time is given by dispersion rate $\left(d, \mathrm{~m}^{2} / \mathrm{s}\right.$ ). In Eqs. (1) to (3), I is the inhaled mass (in $\mathrm{g}$ ), $\mathrm{b}$ is the background concentration (in $\mathrm{g} / \mathrm{m}^{3}$ ), $r_{m}$ is the respiration rate (in $\mathrm{m}^{3} / \mathrm{s}$ ) of the driver (driving vehicle type $\mathrm{m}$ ), $\mathrm{p}_{\mathrm{m}}$ is the penetration rate of vehicle type $\mathrm{m}, \mathrm{O}_{\mathrm{m}}$ is the occupancy of vehicle type $\mathrm{m}$.

The travel time is explicitly included in Eq. (2) i.e. exposure increases with travel time irrespective of the fact that agent is traveling under stop-and-go traffic state or under free-flow traffic state. On the other hand, Eq. (3) incorporates travel time implicitly i.e. longer travel time due to congestion would increase total emissions (e) whereas longer travel times due to detours in areas with low background pollutants would not increase on-road air pollution exposure.

In this study, the following assumptions are made for the parameters in Eqs. (2) and (3).

- The occupancy rate is 1.2 for car (Bigazzi and Figliozzi, 2013) and 1.0 for bicycle and motorcycle.

- Though, different respiration rates are reported for male, female. This study does not differentiate agents based on their gender. Therefore, respiration rate is assumed as $0.66 \mathrm{~m}^{3} / \mathrm{h}$ for motorcyclists (Bigazzi et al., 2015), $0.66 \mathrm{~m}^{3} / \mathrm{h}$ for cars and $3.06 \mathrm{~m}^{3} / \mathrm{h}$ for cyclists (Int Panis et al., 2010).

- The penetration rate is assumed as 1.0 for bicycle and motorcycle, and 0.8 for car (Bigazzi and Figliozzi, 2013). Same penetration rate is assumed for all pollutants.

- Though, the dispersion rate depends on the source height, receptor height, wind speed, wind angle, width of link etc., a mean value of $9 \mathrm{~m}^{2} / \mathrm{s}$ is taken for the present study (Bigazzi and Figliozzi, 2013; Bigazzi et al., 2015).

$$
\begin{aligned}
& I=I_{1}+I_{2} \\
& I_{1}=b \cdot t \cdot r_{m} \cdot p_{m} \cdot O_{m} \\
& I_{2}=\Sigma e / d \cdot r_{m} \cdot p_{m} \cdot O_{m}
\end{aligned}
$$

\subsection{Integration of the model}

A schematic for the integration of the on-road air pollution exposure model with a transport simulation framework and emission modeling tool is shown in Fig. 1. Whenever, an agent leaves a link, emissions (e.g. $\mathrm{NO}_{2}, \mathrm{PM}_{2.5}$ etc.) are 
computed using the emission modeling tool. The emissions (e) are calculated for free flow and stop-\&-go traffic states. However, for simplification, total value is averaged over the link for exposure calculation.

Similar to other vehicle attributes, the mode specific information (e.g. occupancy, breathing rate of the driver, penetration rate etc.) are stored with the vehicle type. Further, whenever, an agent enters a link, it is registered as a receptor. Emissions from all leaving vehicles on the entered link are collected until the receptor leaves the link. The travel time of the receptor on the link is observed from the transport model. Thus, dynamic, agent- and link-specific on-road air pollution exposure is computed.

\section{Application to the real-world case study}

For this study, a real-world case study of Patna, India is chosen. Patna is the second largest city in eastern India and situated along the river 'Ganga' and spread from east to west. Fig. 2 shows three major arterials running in east-west direction; they are namely: 'Ashok Rajpath', 'Old bypass' and 'New bypass'. Transport, industry, residential, dust, open-burning, brick kiln etc. are major contributors for air pollution in Patna. Number of premature deaths related to exposure of PM pollutants in 2012 are estimated to about 2600 (Guttikunda and Jawahar, 2014). Except the rainy season (Jul-Aug), concentrations of PM2.5, PM10 and other pollutants are very high. The situation is likely to become severe in the business-as-usual scenario (Guttikunda and Jawahar, 2014).

The Patna scenario is imputed using the data from Patna Comprehensive mobility plan (TRIPP et al., 2009). The study area of Patna includes 72 zones ('ward') of Patna Municipal corporation. The initial calibrated scenario is taken from Agarwal et al. (2017b); Agarwal (2017) and briefly presented next.

The travel demand of Patna is categorized in two categories i.e. urban and external. The synthetic population for

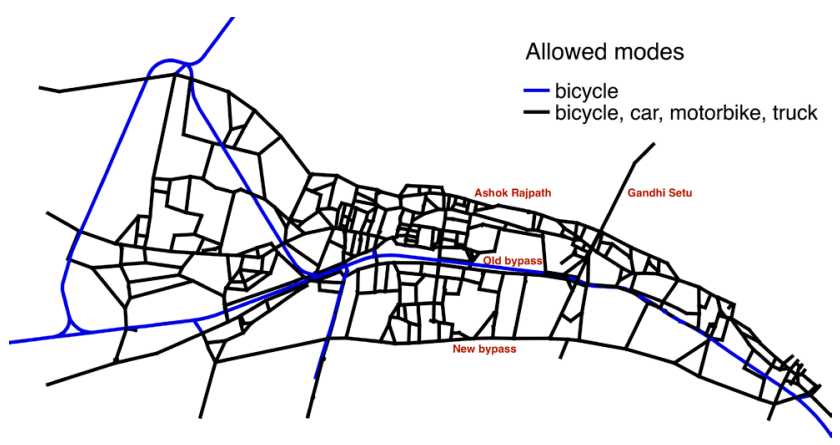

Fig. 2 Patna network, major arterials and bicycle superhighway urban travel demand is generated using a household trip diary survey (TRIPP et al., 2009) which is a part of the comprehensive mobility plan (CMP). A $10 \%$ sample of the whole population is used for the simulation which contains 132,780 agents. The urban travelers use bicycle, car, motorbike, public transport (PT) or walk modes. The share of these modes is $33 \%, 2 \%, 14 \%, 22 \%$ and $29 \%$ respectively. The external travel demand is further classified in commuters and through traffic. The former commutes from Patna to nearby areas or vice versa whereas the latter is the traffic passing through Patna. The external demand is generated from mid-block traffic counts at various cordon stations and origin-destination survey. For this, a Bayesian framework-based calibration technique (Flötteröd et al., 2011; Flötteröd, 2009) is used which implicitly models location-choice (see Agarwal et al., 2017b, for details about the calibration procedure). The calibrated scenario is further used for a "Business-As-Usual" (BAU) scenario and a policy scenario (Agarwal et al., 2017a).

The background concentrations of the concerned pollutants for Patna are given in Table 1. These values are observed at "IGSC Planetarium Complex, Patna - BSPCB" monitoring station. In absence of other values, the same values are assumed for different parts of Patna. As shown in Table 1, background concentrations are considered for four different days at an interval of two months, i.e. covering from winter to summer seasons.

\section{Results}

\subsection{Importance of background concentration}

Table 2 shows a comparison of inhaled mass (dose) per trip by drivers of different vehicle types for three different days and inhaled mass per trip if existing pollutant levels are not considered (i.e. only traffic-related air pollution exposure is considered). In the latter, the inhaled mass per trip is very low (see Table 2) while comparing to the values in literature (O'Donoghue et al., 2007; Chaney et al., 2017). For instance, the estimated inhaled dose of $\mathrm{PM}_{2.5}$ for a cyclist is about $2.78 \mu \mathrm{g}$ only for a trip of about $2.7 \mathrm{~km}$ in Salt Lake City, Utah (USA) (Chaney et al., 2017). Including background air quality in the estimation of exposure, the

Table 1 Background concentration (in $\mu \mathrm{g}$ ) in Patna. (CPCB, n.d.)

\begin{tabular}{lcccc}
\hline Pollutant: & $22-11-2017$ & $22-01-2018$ & $22-03-2018$ & $22-05-2018$ \\
\hline $\mathrm{PM}_{2.5}$ & 217.36 & 201.16 & 174.79 & 86.54 \\
$\mathrm{NO}_{2}$ & 116.79 & 44.79 & 24.48 & 7.65 \\
$\mathrm{CO}$ & 1410.0 & 3470.0 & 2140.0 & 1120.0 \\
$\mathrm{SO}_{2}$ & 21.44 & 49.82 & 52.57 & 43.58 \\
\hline
\end{tabular}


Table 2 Inhaled dose (in $\mu \mathrm{g}$ per trip)

\begin{tabular}{|c|c|c|c|c|}
\hline & $\mathrm{CO}$ & $\mathrm{NO}_{2}$ & $\mathrm{PM}_{2.5}$ & $\mathrm{SO}_{2}$ \\
\hline & \multicolumn{4}{|c|}{ traffic related air pollution exposure only } \\
\hline bicycle & 23.21 & 0.071 & 0.0208 & 0.0016 \\
\hline car & 15.11 & 0.146 & 0.0482 & 0.0023 \\
\hline \multirow[t]{2}{*}{ motorbike } & 14.82 & 0.034 & 0.0093 & 0.0009 \\
\hline & \multicolumn{4}{|c|}{22 Nov. 2017} \\
\hline bicycle & 1024.93 & 83.04 & 154.44 & 15.23 \\
\hline car & 528.57 & 42.67 & 79.20 & 7.81 \\
\hline \multirow[t]{2}{*}{ motorbike } & 267.66 & 20.98 & 38.98 & 3.84 \\
\hline & \multicolumn{4}{|c|}{22 Jan. 2018} \\
\hline bicycle & 2488.43 & 31.83 & 142.93 & 35.39 \\
\hline car & 1278.74 & 16.42 & 73.30 & 18.14 \\
\hline \multirow[t]{2}{*}{ motorbike } & 637.04 & 8.05 & 36.08 & 8.93 \\
\hline & \multicolumn{4}{|c|}{22 Mar. 2018} \\
\hline bicycle & 1543.55 & 17.46 & 124.20 & 37.35 \\
\hline car & 794.41 & 9.06 & 63.70 & 19.15 \\
\hline \multirow[t]{2}{*}{ motorbike } & 398.55 & 4.42 & 31.35 & 9.43 \\
\hline & \multicolumn{4}{|c|}{22 May 2018} \\
\hline bicycle & 818.90 & 5.50 & 61.50 & 30.96 \\
\hline car & 422.97 & 2.93 & 31.56 & 15.87 \\
\hline motorbike & 215.65 & 1.40 & 15.53 & 7.82 \\
\hline
\end{tabular}

inhaled mass per trip increases significantly. This emphasizes the importance of including background pollutant levels in the model as well as in the decision-making process of individual travelers.

Further, the inhaled masses for 22 May 2018 are significantly lower than inhaled masses on typical winter days (Nov.-Jan.). However, these values are still higher than in the case when only traffic-related air pollution exposure is considered. This indicates that if background pollutants are significantly higher than national standards set by various authorities (e.g. CPCB, 2009), lowering traffic on the roads using short-term policy measures (e.g. oddeven scheme, car-pooling) is unlikely to reduce the overall air pollution levels. However, some positive effects can be observed. For instance, (i) as a consequence of lesser traffic, the travel times will decrease which will reduce the exposed duration (see Eq. (2)) as well as reduce the emissions from the vehicles (See Eq. (3)) (ii) staying home will reduce the number of exposed persons directly.

Table 2 also compares the inhaled masses for drivers of different modes. The inhaled dose per trip for cyclists is about 2 times higher than inhaled dose per trip for car drivers/passengers and about 4 times higher than motorbike riders. Higher inhaled dose for cyclists is also found in previous studies (Chaney et al., 2017; O'Donoghue et al., 2007). Even though the average trip times of cyclists and motorbike drivers are in similar range (14.7 min and $17.4 \mathrm{~min}$ for cyclists and motorbike drivers respectively), the exposure per trip for cyclists is higher because of higher breathing rate of cyclists. Interestingly, the exposure of car drivers is higher than motorbike riders due to their longer travel distances and travel times and almost similar penetration rates (see assumptions in Section 2.3).

\subsection{Spatial Analysis}

Fig. 3 shows a comparison of mean $\mathrm{PM}_{2.5}$ per $\mathrm{km}$ for 22 Nov. 2017 and 22 May 2018 i.e. worst and best background concentration from Table 1 . The $\mathrm{PM}_{2.5}$ per $\mathrm{km}$ is averaged over all trips by mapping the trips to the travelers' home zones. It is assumed that 22 Nov. 2017 is a representative day for winter season and 22 May 2018 is a representative day for summers. From this, it is clear that for every zone, averaged inhaled mass of $\mathrm{PM}_{2.5}$ per $\mathrm{km}$ in winter is significantly higher than in summer season which is also found in literature. Clearly, this is a consequence of higher background concentration. Interestingly, Fig. 3a exhibits that central zones of Patna municipal corporation are most affected (red zones). These zones include the central business district, railway station, educational institutions etc. Thus, in addition to on road air pollution exposure, it is more likely that people living in these zones are also significantly affected by the roadside air pollution exposure.
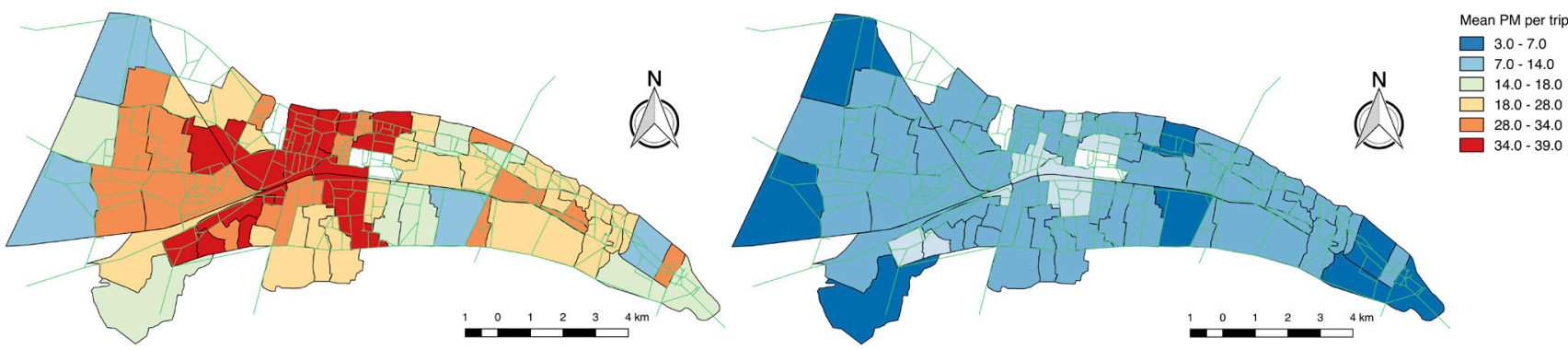

Fig. 3 Mean $\mathrm{PM}_{2.5}(\mu \mathrm{g} / \mathrm{km})$ per trip mapped to home zones at different days (a) 22 Nov. 2017 (b) 22 May 2018 


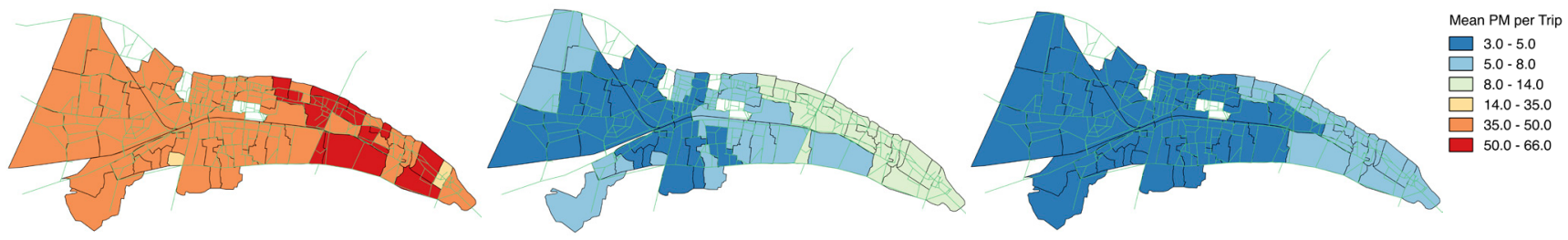

Fig. 4 A comparison of inhaled $\mathrm{PM}_{2.5}(\mu \mathrm{g} / \mathrm{km})$ per trip mapped to home zones for different modes on 22 Nov. 2017 (a) bicycle (b) car (c) motorbike

In order to show the exposure for drivers of different modes, a comparison of the inhaled mass of $\mathrm{PM}_{2.5}$ for different modes on 22 Nov. 2017 is shown in Fig. 4. Similar to Fig. 3, $\mathrm{PM}_{2.5}$ per $\mathrm{km}$ (in $\mu \mathrm{g} / \mathrm{km}$ ) is averaged over all trips by mapping the trips of the travelers' home zones. As discussed and pointed in Section 4.1, the cyclists in all zones are most affected and car drivers are least affected by on road air pollution exposure. Comparing with aggregated over all zones (see Fig. 3a), overall spatial pattern is completely different i.e. instead of central zones, eastern zones of Patna are most exposed. This happens because cyclists make most trips and are concentrated in eastern part of Patna.

\subsection{Impact on bicycle relevant policies}

A bicycle superhighway is proposed along the existing railway line to handle the high bicycle share in Patna (Agarwal et al., 2017a). Hereon, this policy is referred as 'BSH-b'. Further, the authors demonstrate that in the BSH-b policy scenario, the overall exhaust emission decreases. However, the effect of on-road air pollution exposure in the decision-making process of travelers is excluded. As shown in Sections 4.1 and 4.2, cyclists are most affected user-group by on-road air pollution exposure. Though, the inclusion of on-road air pollution exposure in the choice model is beyond the scope of the present study, a few policy relevant implications are discussed here.

Table 3 shows the changes in total inhaled mass (in $\mu \mathrm{g}$ per trip) for BSH-b with respect to the business-as-usual scenario (see Sections 4.1 and 4.2). The introduction of a fast bicycle superhighway makes the bicycle mode more attractive. Agents with short distance car/motorbike/other trips switch to the bicycle mode and increase the bicycle share from $32 \%$ to $48 \%$. A significantly higher number of bicycle trips increases congestion on the bicycle superhighway (see Fig. 5) and results in higher travel time i.e. the average trip times for cyclists increase from $14.1 \mathrm{~min}$ per trip to 20.8 min per trip (due to lower efforts and higher comfort on bicycle superhighway). Thus, more cyclists and longer travel times directly affect the on-road air pollution exposure i.e. the inhaled mass per trip in BSH-b policy scenario
Table 3 Changes in inhaled dose (in $\mu$ g per trip) for BSH-b policy scenario with respect to business-as-usual scenario (22 Nov. 2017).

\begin{tabular}{lrrrc}
\hline & $\mathrm{CO}$ & $\mathrm{NO}_{2}$ & $\mathrm{PM}_{2.5}$ & $\mathrm{SO}_{2}$ \\
\hline bicycle & 390.49 & 33.34 & 62.11 & 6.13 \\
car & 2.58 & 0.40 & 0.75 & 0.07 \\
motorbike & 9.12 & 0.89 & 1.65 & 0.16 \\
\hline
\end{tabular}

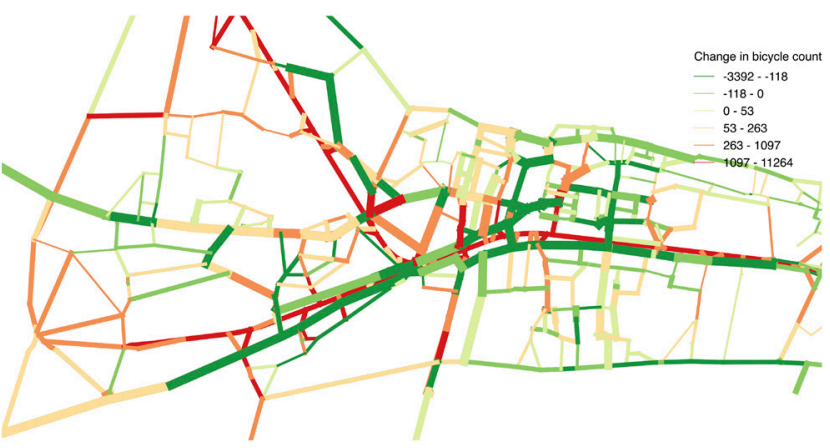

Fig. 5 Change in bicycle count for business-as-usual scenario with respect to BSH-b policy scenario (green and red colors represent a decrease and increase in bicycle traffic respectively). Thicker lines represent higher capacities of links (e.g. arterials).

is $\approx 40 \%$ higher than in the business-as-usual scenario corresponding to background concentrations on 22 Nov. 2017. Fig. 5 shows the change in bicycle traffic on various links with respect to the BSH-b policy scenario. The bicycle traffic on major arterials decreases and increases significantly on bicycle superhighway which passes through central-business-district area. The central- business district has higher traffic-related air pollution exposure i.e. rerouting agents to bicycle superhighway is likely to increase their exposure from traffic related air pollution exposure. Since, short distance trips from car, motorbike switches to bicycle mode, the average inhaled mass per trip for drivers of motorized traffic (e.g. car, motorbike) increases marginally due to remaining longer trips.

A comparison between mean $\mathrm{PM}_{2.5}$ per trip mapped to the travelers' home zones is shown in Fig. 6. Clearly, due to increase in the number of cyclists for BSH-b scenario, average $\mathrm{PM}_{2.5}$ per trip increases for other zones. Since, the new cyclists are not captive to the bicycle mode, 


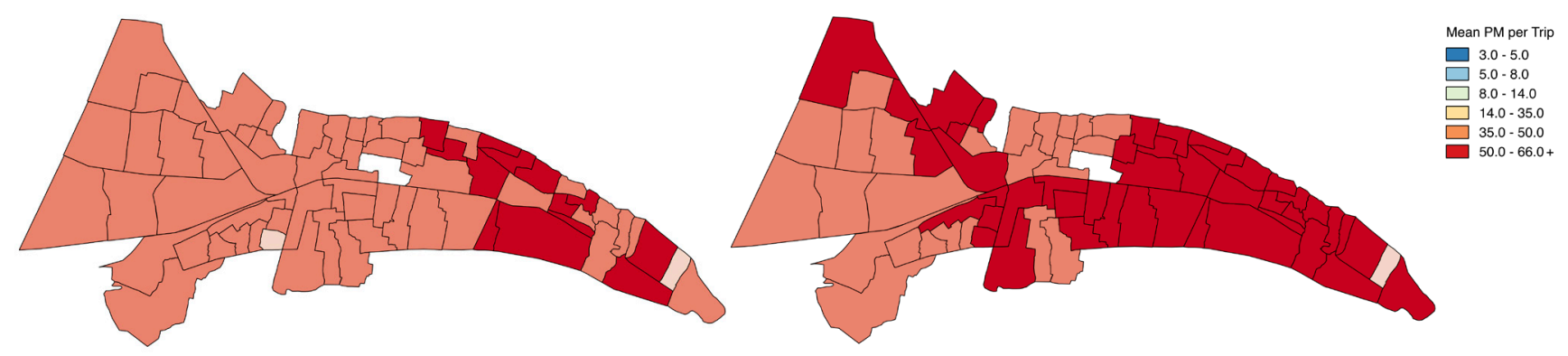

Fig. 6 Mean $\mathrm{PM}_{2.5}(\mu \mathrm{g} / \mathrm{km})$ per trip for cyclists in business-as-usual and BSH-b scenarios

considering air pollution exposure, travelers can opt not to cycle i.e. the gain in the share of bicycle by Agarwal et al. (2017a) is overestimated.

Agarwal et al. (2017a) propose the bicycle superhighway on ground parallel to the railway track and major arterials, however, it is likely that in another real-world scenario, a bicycle superhighway is over head. In the latter case, the cyclists are not directly or to a lesser extent affected by the exhaust emissions but still exposed to the background air pollution. With the foregoing discussion, it is clear that on-road air pollution exposure should be considered in the design and evaluation of transport policies.

\section{Conclusions}

This study provides an approach to estimate the time-dependent, person- and mode-specific on-road air pollution exposure. The approach considers the impact of background air pollution concentrations, the vehicle penetration rate, mode-specific breathing rates of drivers, the vehicle occupancy etc. The travel time is explicitly considered with background concentration whereas implicitly considered with the vehicular exhaust emissions, i.e. longer travel time due to detours in areas with a low background pollutant concentration and free-flow state would not increase the on-road air pollution exposure.

A case study of Patna, India is presented and on-road exposures to drivers of car, motorbike and bicycle are computed. Even though, the travel times for bicycle and motorbike trips differ marginally, the total inhaled dose per trip is highest for bicycle trips, mainly due to the higher respiration rate. With a comparison of air pollution exposure with and without background concentration on different days of the year, it is shown that the contribution of the background concentration has a major effect on the total mass inhaled. Further, with the help of spatial analyses, zones in which most residents are affected, are identified. Finally, the outcome is compared with a policy measure in which a bicycle superhighway is proposed for Patna. It is found that, a bicycle superhighway is likely to increase the on-road air pollution exposure per trip to cyclists by $40 \%$ which is likely to reduce the gain in bicycle share. This emphasize that in future, air pollution exposures should be incorporated in the decision-making process of travelers and in the design of the facilities. In addition to this, the decision of cycling would also depend if health benefits from cycling can compensate the damages to the health due to air pollution exposure.

In the present study, the background air quality is very poor which results in very high importance during estimation of inhaled dose per trip. However, the background pollutants may not be equally important in the developed world where air pollution levels are below threshold levels. In such cases, the traffic-related air pollution exposure can become significant. Policies in which facilities for non-motorized modes of transport are designed needs consideration of background as well as traffic-related air pollution exposure. Inclusion of near-road air pollution exposure to the persons performing activities (e.g. home, work, education, leisure, etc.) remains a future task.

\section{Acknowledgement}

This paper is a previous version of the paper presented at the NECTAR Cluster 7 Workshop on Social and Health Issues in Transportation, 2018. 


\section{References}

Agarwal, A. (2017) "Mitigating negative transport externalities in industrialized and industrializing countries", PhD thesis, Technische Universität Berlin. https://doi.org/10.14279/depositonce-5825

Agarwal, A., Kickhöfer, B. (2018) "The correlation of externalities in marginal cost pricing: lessons learned from a real-world case study", Transportation, 45(3), pp. 849-873. https://doi.org/10.1007/s11116-016-9753-z

Agarwal, A., Lämmel, G. (2016) "Modeling Seepage Behavior of Smaller Vehicles in Mixed Traffic Conditions Using an Agent Based Simulation", Transportation in Developing Economies, 2(2), pp. 1-12. https://doi.org/10.1007/s40890-016-0014-9

Agarwal, A., Zilske, M., Rao, K. R., Nagel, K. (2015) "An Elegant and Computationally Efficient Approach for Heterogeneous Traffic Modelling Using Agent Based Simulation", Procedia Computer Science, 52, pp. 962-967.

https://doi.org/10.1016/j.procs.2015.05.173

Agarwal, A., Ziemke, D., Nagel, K. (2017a) "Bicycle superhighway: an environmentally sustainable policy for urban transport", VSP Working Paper 17-16, TU Berlin. [online] Available at: https://svn. vsp.tu-berlin.de/repos/public-svn/publications/vspwp/2017/17-16/ [Accessed: 23 May 2018]

Agarwal, A., Ziemke, D., Nagel, K. (2017b) "Calibration of heterogeneous traffic scenario in an agent-based simulation framework", presented at 4th Conference of the Transportation Research Group of India (CTRG-2017), Bombay, India, Dec. 17-20, 2017.

Agarwal, A., Lämmel, G., Nagel, K. (2018) "Incorporating within link dynamics in an agent-based computationally faster and scalable queue model", Transportmetrica A: Transport Science, 14(5-6), pp. 520-541.

https://doi.org/10.1080/23249935.2017.1364802

Balmer, M., Rieser, M., Meister, K., Charypar, D., Lefebvre, N., Nagel, K., Axhausen, K. W. (2009) "MATSim-T: Architecture and Simulation Times", In: Bazzan, A., Klügl, F. (eds.) Multi-Agent Systems for Traffic and Transportation, IGI Global, Hershey, PA, pp. 57-78. https://doi.org/10.4018/978-1-60566-226-8.ch003

Bigazzi, A. Y., Figliozzi, M. A. (2013) "Marginal costs of freeway traffic congestion with on-road pollution exposure externality", Transportation Research Part A: Policy and Practice, 57, pp. 12-24. https://doi.org/10.1016/j.tra.2013.09.008

Bigazzi, A. Y., Figliozzi, M. A. (2014) "Review of Urban Bicyclists' Intake and Uptake of Traffic-Related Air Pollution", Transport Reviews, 34(2), pp. 221-245.

https://doi.org/10.1080/01441647.2014.897772

Bigazzi, A. Y., Figliozzi, M. A., Clifton, K. J. (2015) "Traffic Congestion and Air Pollution Exposure for Motorists: Comparing Exposure Duration and Intensity", International Journal of Sustainable Transportation, 9(7), pp. 443-456, 2015.

https://doi.org/10.1080/15568318.2013.805345

Cetin, N. (2005) "Large-Scale parallel graph-based simulations", PhD Thesis, Swiss Federal Institute of Technology (ETH), Zürich, Switzerland.
Chaney, R. A., Sloan, C. D., Cooper, V. C., Robinson, D. R., Hendrickson, N. R., McCord, T. A., Johnston, J. D. (2017) "Personal exposure to fine particulate air pollution while commuting: An examination of six transport modes on an urban arterial roadway", PLoS ONE, 12(11). https://doi.org/10.1371/journal.pone.0188053

CPCB (2009) "National ambient air quality standards", Central Pollution Control Board.

CPCB (n.d.) "Central Control Room for Air Quality Management - All India". [online] Available at: http://cpcb.nic.in/real-time-air-quality-data/ [Accessed: 23 May 2018]

Creutzig, F., He, D. (2009) "Climate change mitigation and co-benefits of feasible transport demand policies in Beijing", Transportation Research Part D: Transport and Environment, 14(2), pp. 120-131. https://doi.org/10.1016/j.trd.2008.11.007

de Nazelle, A., Rodríguez, D. A., Crawford-Brown, D. (2009) "The built environment and health: Impacts of pedestrian-friendly designs on air pollution exposure", Science of The Total Environment, 407(8), pp. 2525-2535.

https://doi.org/10.1016/j.scitotenv.2009.01.006

Flötteröd, G. (2009) "Cadyts - a free calibration tool for dynamic traffic simulations, In: Swiss Transport Research Conference, Monte Verità, Ascona, Switzerland. [online] Available at: http://www. strc.ch/2009/Floetteroed.pdf [Accessed: 23 May 2018]

Flötteröd, G., Bierlaire, M., Nagel, K. (2011) "Bayesian Demand Calibration for Dynamic Traffic Simulations", Transportation Science, 45(4), pp. 541-561, 2011. https://doi.org/10.1287/trsc.1100.0367

Gawron, C. (1998) "An Iterative Algorithm to Determine the Dynamic User Equilibrium in a Traffic Simulation Model", International Journal of Modern Physics C, 9(3), pp. 393-407. https://doi.org/10.1142/S0129183198000303

Gulliver, J., Briggs, D. J. (2005) "Time-space modeling of journey-time exposure to traffic- related air pollution using GIS", Environmental Research, 97(1), pp. 10-25. https://doi.org/10.1016/j.envres.2004.05.002

Guttikunda, S. K., Jawahar, P. (2014) "Characterizing Patna's Ambient Air Quality and Assessing Opportunities for Policy Intervention", UrbanEmissions.Info, New Delhi, India.

Horni, A., Nagel, K., Axhausen, K. W. (eds.) (2016) "The Multi-Agent Transport Simulation MATSim", Ubiquity, London, UK. https://doi.org/10.5334/baw

Hülsmann, F., Gerike, R., Kickhöfer, B., Nagel, K., Luz, R. (2011) "Towards a multi agent-based modeling approach for air pollutants in urban regions", In: Conference on "Luftqualität an Straßen", Bergisch Gladbach, Germany, pp. 144-166.

Int Panis, L., de Geus, B., Vandenbulcke, G., Willems, H., Degraeuwe, B., Bleux, N., Mishra, V., Thomas, I., Meeusen, R. (2010) "Exposure to particulate matter in traffic: A comparison of cyclists and car passengers", Atmospheric Environment, 44(19), pp. 2263-2270. https://doi.org/10.1016/j.atmosenv.2010.04.028 
Kaddoura, I., Agarwal, A., Kickhöfer, B. (2017) "Simulation-based optimization of congestion, noise and air pollution costs: the impact of transport users' choice dimensions", presented at ITEA Annual Conference and School on Transportation Economics, Barcelona, Spain, June 19-23, 2017.

Kickhöfer, B., Kern, J. (2015) "Pricing local emission exposure of road traffic: An agent-based approach", Transportation Research Part D: Transport and Environment, 37, pp. 14-28. https://doi.org/10.1016/j.trd.2015.04.019

Kickhöfer, B., Nagel, K. (2016) "Towards High-Resolution First-Best Air Pollution Tolls", Networks and Spatial Economics, 16(1), pp. $175-198$.

https://doi.org/10.1007/s11067-013-9204-8

Kickhöfer, B., Hülsmann, F., Gerike, R., Nagel, K. (2013) "Chapter 9: Rising car user costs: comparing aggregated and geo-spatial impacts on travel demand and air pollutant emissions", In: Vanoutrive, T., Verhetsel, A. (eds.) Smart Transport Networks: Market Structure, Sustainability and Decision Making, NECTAR Series on Transportation and Communications Networks Research, Edward Elgar Publishing Ltd., Cheltenham, UK, pp. 180-207. https://doi.org/10.4337/9781782548331.00014

Nagel, K., Flötteröd, G. (2012) "Agent-based traffic assignment: Going from trips to behavioural travelers", In: Pendyala, R. M., Bhat, C. R. (eds.) Travel Behaviour Research in an Evolving World: Selected papers from the 12th International Conference on Travel Behaviour Research, 1st ed., International Association for Travel Behaviour Research, (IATBR), Jaipur, India, pp. 261-294.
Nagel, K., Kickhöfer, B., Horni, A., Charypar, D. (2016) "A Closer Look at Scoring", In: Horni, A., Nagel, K., Axhausen, K. W. (eds.) The Multi-Agent Transport Simulation MATSim, Ubiquity, London, UK. https://doi.org/10.5334/baw.3

O'Donoghue, R. T., Gill, L. W., McKevitt, R. J., Broderick, B. (2007) "Exposure to hydrocarbon concentrations while commuting or exercising in Dublin", Environment International, 33(1), pp. 1-8. https://doi.org/10.1016/j.envint.2006.05.005

TRIPP, iTrans, VKS (2009) "Comprehensive mobility plan for Patna urban agglomeration area", Department of Urban Development, Government of Bihar, India.

van Essen, H., Schroten, A., Otten, M., Sutter, D., Schreyer, R., Zandonella, C., Maibach, M., Doll, C. (2011) "External costs of transport in Europe", Infras, Frauenhofer ISI, CE Delft, Delft, The Netherlands, Publication code: 11.4215.50.

Zhang, K., Batterman, S. (2013) "Air pollution and health risks due to vehicle traffic", Science of The Total Environment, 450-451, pp. 307-316.

https://doi.org/10.1016/j.scitotenv.2013.01.074 